\begin{abstract}
Haben Sie Anregungen für den Hausarzt-Reporter? Ein wichtiges aktuelles Diskussionsthema, ein unerhörtes Erlebnis aus Alltag oder Bürokratie, oder vielleicht einfach nur eine interessante Hausarztpraxis? Melden Sie sich!
\end{abstract}

Fax:089/203043-31364 E-Mail: cornelius.heyer@springer.com

\title{
In Rio gewinnt, wer gesund bleibt
}

\author{
Zikavirus und Dengue-Fieber, miese Hygienestandards, inakzeptable Wasserqualität \\ - die Olympischen Spiele in Rio de Janeiro stehen bisher nicht im Ruf, ein Fest für die \\ Gesundheit zu werden. Der Allgemeinmediziner Dr. Ulrich Kau, Verbandsarzt der \\ deutschen Ruderer, berichtet von den Vorbereitungen.
}

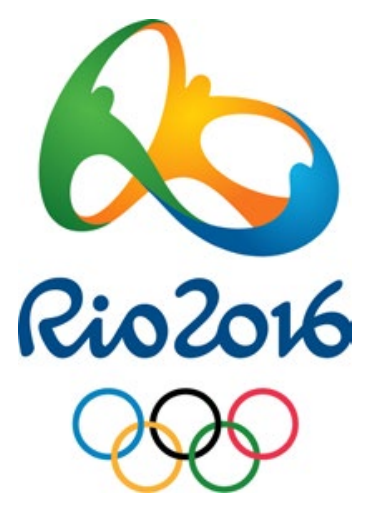

_ In meinen zehn Jahren als Verbandsarzt habe ich schon Einiges erlebt. In Peking 2008 erkrankten zum Halbfinale neun Sportler an der Grippe, was zwei Medaillenhoffnungen platzen ließ. Bei einer Weltmeisterschaft infizierten sich 35 Sportler mit dem Norovirus. Aber die Olympischen Spiele in Rio stellen eine besondere Herausforderung dar.

Die medizinischen Probleme werden in den Medien diskutiert. Einige Kollegen verlangten gar, die Spiele zu verlegen oder gar nicht stattfinden zu lassen. Dies verunsichert natürlich auch unsere Sportler, die sich fundierte Aussagen wünschen. Auf Infoveranstaltungen und in Einzelgesprächen versuchen wir, mit einer realistischen Darstellung $\mathrm{Pa}$ nik zu vermeiden. Die Hauptprobleme sind das Klima, die tropische Mücke und speziell bei uns Ruderern die Wasserqualität der Regattastrecke.

In Brasilien herrschen trotz Winter im Juli Temperaturen von 23-28 Grad bei hoher Luftfeuchtigkeit. Richtige Kleidung, Sonnenschutz und ausreichende Flüssigkeit sind wichtig.

Die Tigermücke hat sich seit der Fußballweltmeisterschaft 2014 enorm verbreitet. Ihr Stich kann die Übertragung des viel diskutierten Zikavirus ermöglichen, was zu grippeähnlichen Sympto-

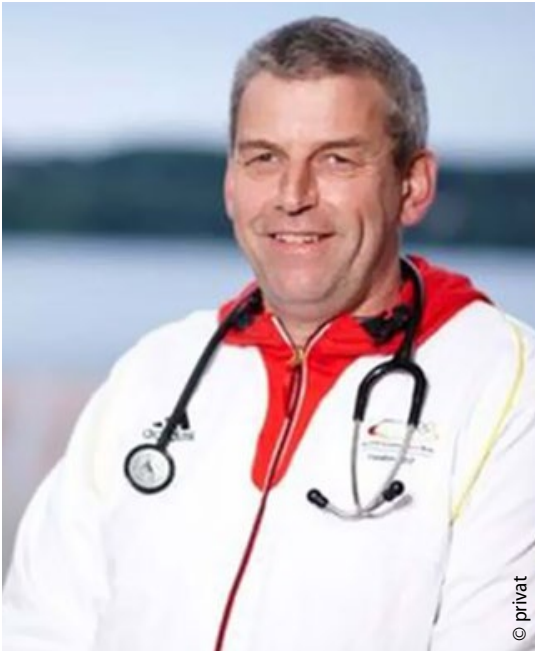

Der Arzt der Ruderer: Dr. Ulrich Kau.

men führt, auch wenn ca. $40-60 \%$ der Betroffenen nicht unter Symptomen leiden. Entscheidend für die Prophylaxe ist der Mückenschutz: lange, helle Kleidung (insbesondere auch Strümpfe), Moskitonetze an den Fenstern und Sprays. Wir besprühen die Kleidung mit einem Icaridin-haltigen Produkt und die Haut mit 50\%igem Diethyltoluamid (DEET).

Auch die sexuelle Übertragung muss vermieden werden. Durch die niedrigere Temperatur in den Hoden kann das Zikavirus dort länger überleben und vom Mann an den Sexualpartner übertragen werden. V. a. falls es zu einer Schwangerschaft kommt, kann dies gravierende Folgen haben, weshalb wir geschützten Verkehr empfehlen - vier Wochen nach den Spielen für Frauen, acht Wochen für Männer.

\section{Wassersport in der Kloake}

Viele Abwasserkanäle Rios enden in der olympischen Regattastrecke, in deren Wasser ein großes Spektrum von Darmkeimen nachgewiesen wurde. Der Wasserkontakt sollte möglichst vermieden werden - was beim Rudern nicht einfach ist. Die Athleten sind deshalb gegen Cholera geimpft worden, da dies laut Studienlage $\mathrm{zu} \quad 20-40 \%$ gegen diese Darmkeime immunisiert. Ebenso werden wir zur Verhinderung von Wundinfektionen nach dem Rudern stets die Hände desinfizieren.

Essen sollten die Sportler nur in der offiziellen Mensa des Olympischen Dorfes. Zum Trinken gibt es abgepackte Getränke vom Veranstalter. Unsere Athleten sind gut vorbereitet. Wir hoffen, sie alle gesund und voll leistungsfähig durch die Wettkämpfe zu bringen!

Dr. Ulrich Kau

- Der Autor ist niedergelassener Hausarzt in Oestrich-Winkel und Leitender Verbandsarzt des Deutschen Ruderverbands. 